\title{
The Impact of Micro-Lecture on College English Teachers' Niche
}

\author{
Junhong Tang, Jing Chen \\ The Foreign Language Department, Baoding University, Baoding, China \\ Email: jessytang99@163.com
}

Received 7 March 2016; accepted 25 March 2016; published 28 March 2016

Copyright (C) 2016 by authors and Scientific Research Publishing Inc.

This work is licensed under the Creative Commons Attribution International License (CC BY).

http://creativecommons.org/licenses/by/4.0/

(c) (i) Open Access

\begin{abstract}
In order to widen college English teachers' ecological niche and promote their teaching ability, we make an empirical study on college English teachers' teaching ability and ecological niche on the basis of Ecological Niche Theory. The paper shows how to take advantage of micro-lectures, make full use of 5C teaching strategies and form multiple teaching and learning evaluation and online teaching and learning community to improve discourse power between students and teacher, to change the role of students and teacher. In this way, college English teachers' teaching ability will be improved greatly.
\end{abstract}

\section{Keywords}

Niche, Discourse, Role

\section{Introduction}

Education in "Internet Plus" time is very different from the traditional education. In the traditional education, it is very difficult and inconvenient for schools, teachers and students to communicate with each other and learn from each other. At the same time, one teacher teaches in one classroom in front of dozens of students, while in "Internet Plus" time, one teacher is able to teach online without the limitation of space, time and the number of students (White, 2011). This is the result of "Internet Plus". Confronted with internet, educators have to deal with so many opportunities and challenges (Chen, 2011). College English teachers must adapt to the times to master the methods of information technology application to meet the learning characteristics of college students (Griffiths \& Keohane, 2013).

"Micro video network course" is abbreviated to "micro-lecture”. It is based on the micro teaching video. It is also a kind of online video course resource which is designed and developed to support contextual and various learning styles according to such learning points as key points, difficult points, and questionable points, learning activities or experiments. 
As a kind of new learning resource, "Micro-lecture" is an important and necessary supplement to the traditional class. With the popularity of the mobile digital products and handheld wireless networks, "micro-lecture" becomes more and more popular in terms of mobile learning, distance learning and online learning. As a result, one of the necessary qualities of college English teachers is to design, produce and use "micro-lecture".

\section{Ecological Niche}

\subsection{The Theory of Trend and Position of Niche}

Niche is an important theory in Ecology. It refers to the relative position and role of a biological unit in the process of interaction with the environment in a particular ecological system (Li, 2008). The niche contains two aspects. One is the state of a biological unit like energy, the amount of resources, adaptability and the level of development of science and technology. It is the result of accumulation of past growth, learn, development of economy or the interaction on the environment. The other is the real influence and force on the environment of the biological unit like rate of energy and material transformation, production or the capacity of occupying the new environment. The combination of these two aspects shows the relative position and role of a particular biological unit in a ecological system (Zhu, 1997).

\subsection{The Trend, Position and Measure of College English Teachers' Teaching Ability}

The niche of college English teacher is the relative position and role in the process of interaction with the various environments in educational ecological system. The niche of teachers is also composed of two aspects. One is "state". It refers to the teaching state of college English teachers and it is a kind of historical accumulation of education, teaching practice. "Trend" is the potential influence of the teacher on teaching environment which determines the future teaching ability trend.

According to the theory of trend and position of niche, the niche of teachers' teaching ability can be calculated by use of the following formula.

$$
N i=\frac{S i+A i P i}{\sum_{j-1}^{n}(S j+A i P i)}(\text { Zhu, 1997) }
$$

In this formula, $i$ and $j$ equal $1,2,3, \ldots, n$. Ni is the relative niche of the teacher $i$. Si is the state of teaching ability of teacher $i$ and $P i$ is the trend of teaching ability of teacher $i$. S $j$ is the state of teaching ability of teacher $j$ and $P j$ is the trend of teaching ability of teacher $j$. Ai and $A j$ are dimension conversion coefficient. The organic combination of state and trend fully reflects the niche breadth of teachers' teaching ability, the niche size. In the above formula, "Si + AiPi" can be seen as the absolute niche of teacher I's teaching ability.

\section{An Empirical Study on the Trend and Position of Niche of Teachers' Teaching Ability}

In order to further show the impact of “micro-lecture” on teachers' teaching ability and niche, we studied 9 college teachers during 4 semesters in 2 years. The 9 college teachers teach the same grade and use the same textbooks. By using the above formula, the relative niche and absolute niche of the 9 college English teachers are calculated. Set the evaluation results of the second semester in 2014-2015 school year as the state metrics of teachers' teaching ability at that time and make the average annual growth rate of evaluation results as the trend metrics of teachers' teaching ability and 1a is the time scale, so dimension conversion coefficient is also 1a. The result is in Table 1

In a certain ecological system, the range of niche of various ecological units is from 0 to 1 , and the sum of it is 1. The greater the niche breadth is, the greater its value is. That is to say, the object we studied plays a more important role in the system. From the above table, we can see the evaluation result of teacher $\mathrm{C}$ in the second semester in 2014-2015 school year is 97.44. 97.44 is lower than 97.56 of teacher H and 98.29 of teacher G. Because the average semester growth rate of teacher $\mathrm{C}$ is greater, his teaching ability niche is higher than teacher $\mathrm{H}$ and teacher $\mathrm{G}$ and it reaches 0.1181 which is the highest in the system. In addition, the evaluation result of teacher $\mathrm{E}$ in the second semester in 2014-2015 school year is higher than teacher D and teacher F, but his niche value, 0.1042 is lower than teacher $\mathrm{D}$ and teacher $\mathrm{F}$ just because of his average variation is -0.19 . The reasons 
Table 1.9 college teachers' niche of teaching ability.

\begin{tabular}{ccccc}
\hline $\begin{array}{c}\text { College English } \\
\text { Teacher }\end{array}$ & $\begin{array}{c}\text { Evaluation Results of the Second } \\
\text { Semester in 2014-2015 }\end{array}$ & $\begin{array}{c}\text { Evaluation Results the Variation of } \\
\text { Each Semester from 2013 to 2015 }\end{array}$ & $\begin{array}{c}\text { Teaching Ability } \\
\text { Absolute Niche }\end{array}$ & $\begin{array}{c}\text { Teaching } \\
\text { Ability Niche }\end{array}$ \\
\hline A & 97.65 & 0.12 & 98.46 & 0.1096 \\
B & 98.29 & 0.54 & 99.25 & 0.1170 \\
C & 97.44 & 0.64 & 99.68 & 0.1181 \\
D & 97.45 & 0.59 & 99.56 & 0.1173 \\
E & 98.55 & -0.19 & 97.53 & 0.1042 \\
F & 97.46 & 0.38 & 98.77 & 0.1155 \\
G & 98.29 & -0.24 & 97.23 & 0.1046 \\
H & 97.56 & -0.43 & 96.13 & 0.1041 \\
I & 97.95 & 0.12 & 98.65 & 0.1096 \\
Total & 880.64 & 0.77 & 885.26 & 1 \\
\hline
\end{tabular}

for these changes are due to the use of micro-lecture. Teacher B, D and F use micro-lecture effectively and efficiently. By use of micro-lecture, these teachers improved the discourse power and changed the roles between teacher and students. The teaching ability and the teaching influence is enhanced at the same time.

It is more reliable to evaluate teachers' teaching ability by use of "state and trend niche theory" (Liu, 2011). In this way, we can consider both the current teaching state and the potential teaching ability.

\section{The Trend of Teachers' Teaching Ability}

In order to meet the requirements of "internet plus" time and to cater to modern college students' learning characteristics, college English teachers are supposed to pay attention to the following points.

\subsection{Improve the Current Discourse Power between Teacher and Students by Use of Micro-Lecture}

Discourse is consistent in semantic and pragmatic. It is a kind of communicative behavior to achieve a certain communicative purpose. It can be both written style and colloquial speech. Discourse secretly controls people's potential logic of language, thoughts and behavior and it is under the conscious. In brief, discourse is what to say, how to say and when to say under certain historical and social circumstances.

Discourse is to use language in proper place, at proper time and according to proper target to think, evaluate, act and communicate to form a social relationship accepted.

Language in use is a kind of tool. With other tools, they design and build things. When we are speaking and writing, we construct "seven things" or "seven realistic blocks". The "seven things" can be called "seven building tasks". It can be showed by Figure 1.

We can make discourse analysis of teachers' classroom language. First, how does this dialogue make things meaningful? Second, how many activities does this dialogue create? Third, how many kinds of relationships does this dialogue bring? Fourth, how many kinds of status can be determined? Fifth, what kind of attitudes does this dialogue towards? Sixth, how does this dialogue connect or disconnect relationships? Seventh, how does this dialogue make certain symbol system better than the other?

\subsection{Change the Roles of Teacher and Students by Use of "Micro-Lecture"}

According to ecological principles, the units in the same niche will compete with each other and their adaptability will be improved. Meanwhile, "symbiotic effect" shows that exchange between individuals and mutual influence will greatly promote the whole group.

In view of this, the teacher can organize the students to make drama performance on such passages which have a strong plot, to make a speech contest or debate on such passages which is inspirational. By means of cooperation in groups and competition among groups, students' competitive and cooperative consciousness can be 


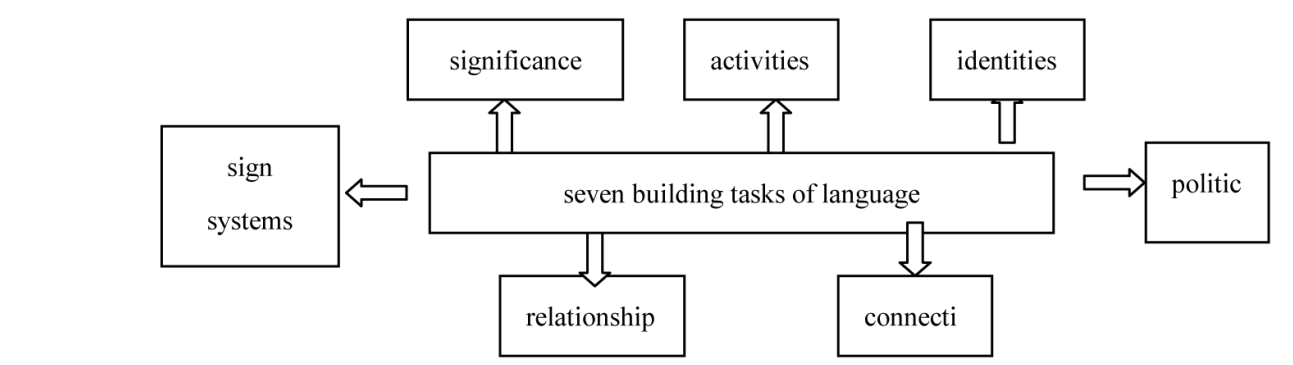

Figure 1. Seven building tasks of language.

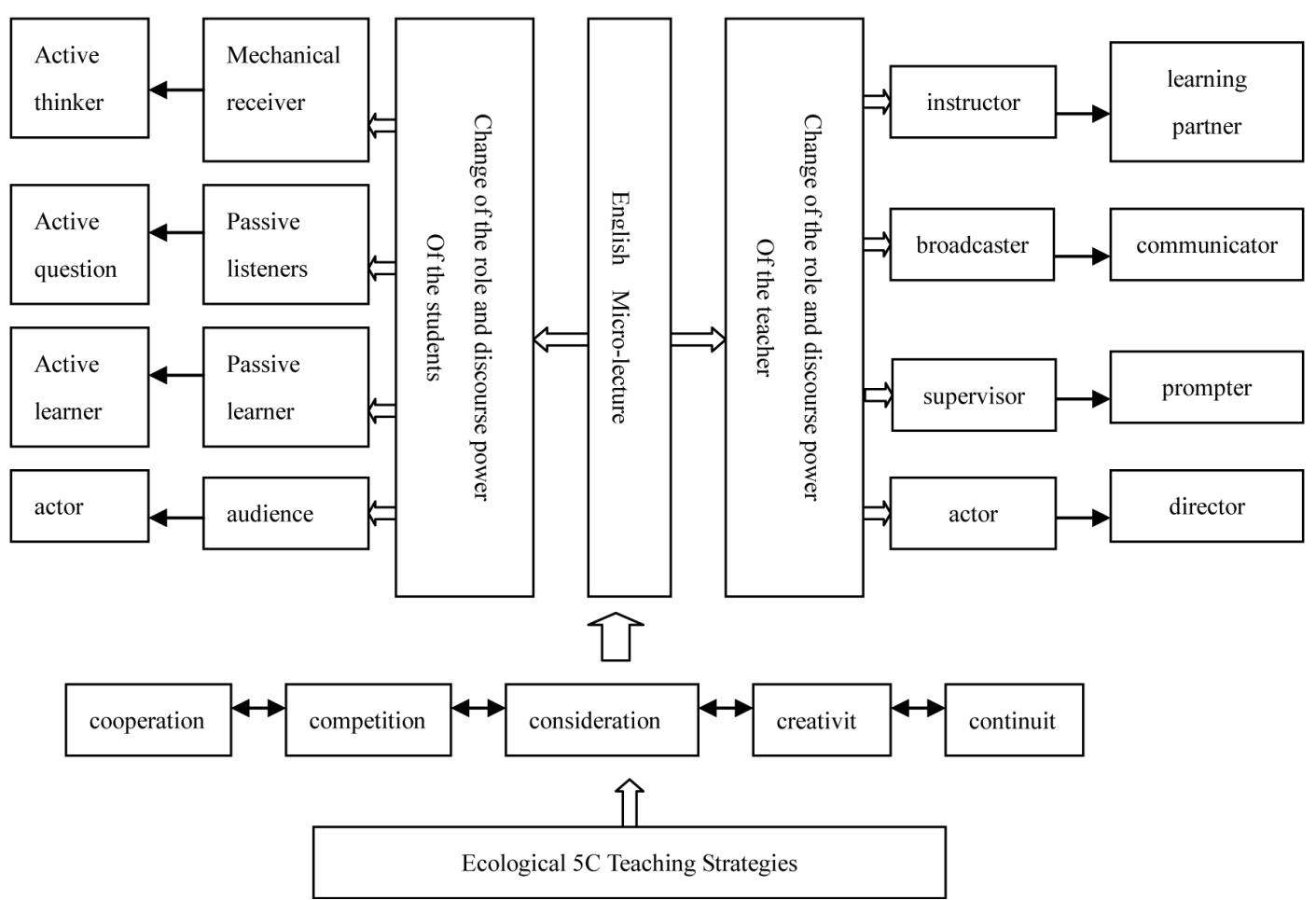

Figure 2. Change of the role and discourse power between the students and teacher by the ecological $5 \mathrm{C}$ teaching strategies.

cultivated and students' strong inspiration to learn English can be promoted. While on some passages which are full of grammar, the teacher should explain in detail in view of students' different English level and personalities. In other words, the teacher is expected to explain English grammars with consideration and creativeness in order to meet all students' requirement.

By use of such teaching strategies as cooperation, competition, consideration and creativity, the teacher's role (Liu, 2014) will change from instructor to learning partner, from broadcaster to communicator, from supervisor to prompter and from actor to director. At the same time, the students' role will change from mechanical receiver to active thinker, from passive listener to active questioner, from passive learner to active learner and from audience to actor (Figure 2).

\subsection{Form Multiple Teaching and Learning Evaluation Methods and Establish Online Teaching and Learning Community}

Multiple teaching and learning evaluation methods (Chapelle \& Douglas, 2010) include mid-term exam, final exam, class presentation, on-and-off-line work, effective questioning, original insights and resource sharing (Figure 3). Mid-term exam and final exam account for $40 \%$ of the final marks and the other parts account for $60 \%$. By this way, the evaluation will change from summative assessment to formative evaluation with diversity 


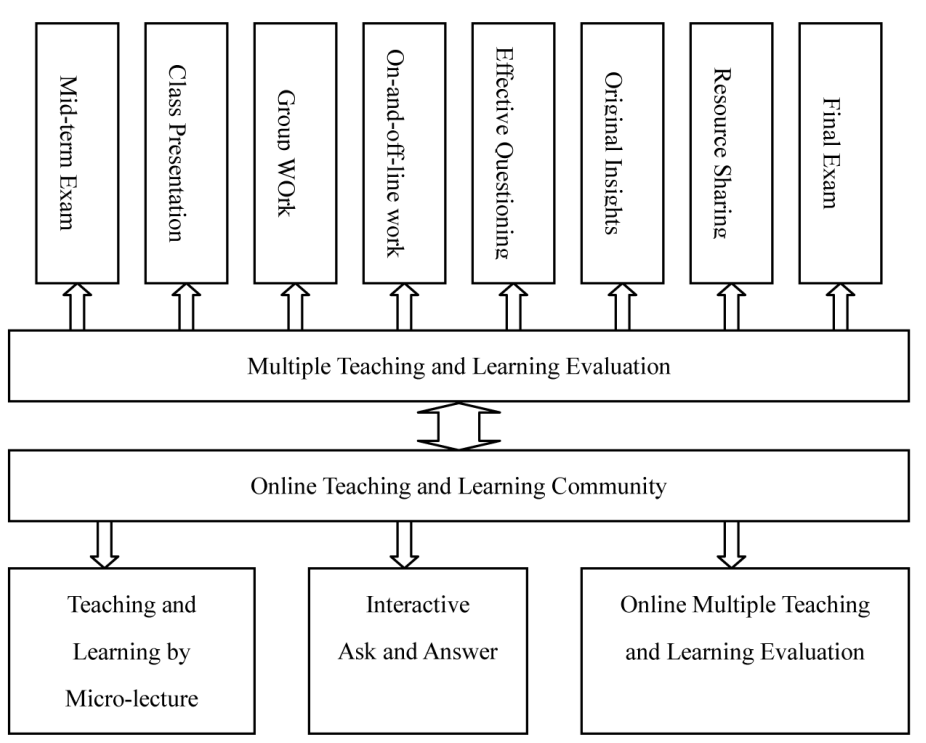

Figure 3. Multiple teaching and learning evaluation and online teaching and learning community.

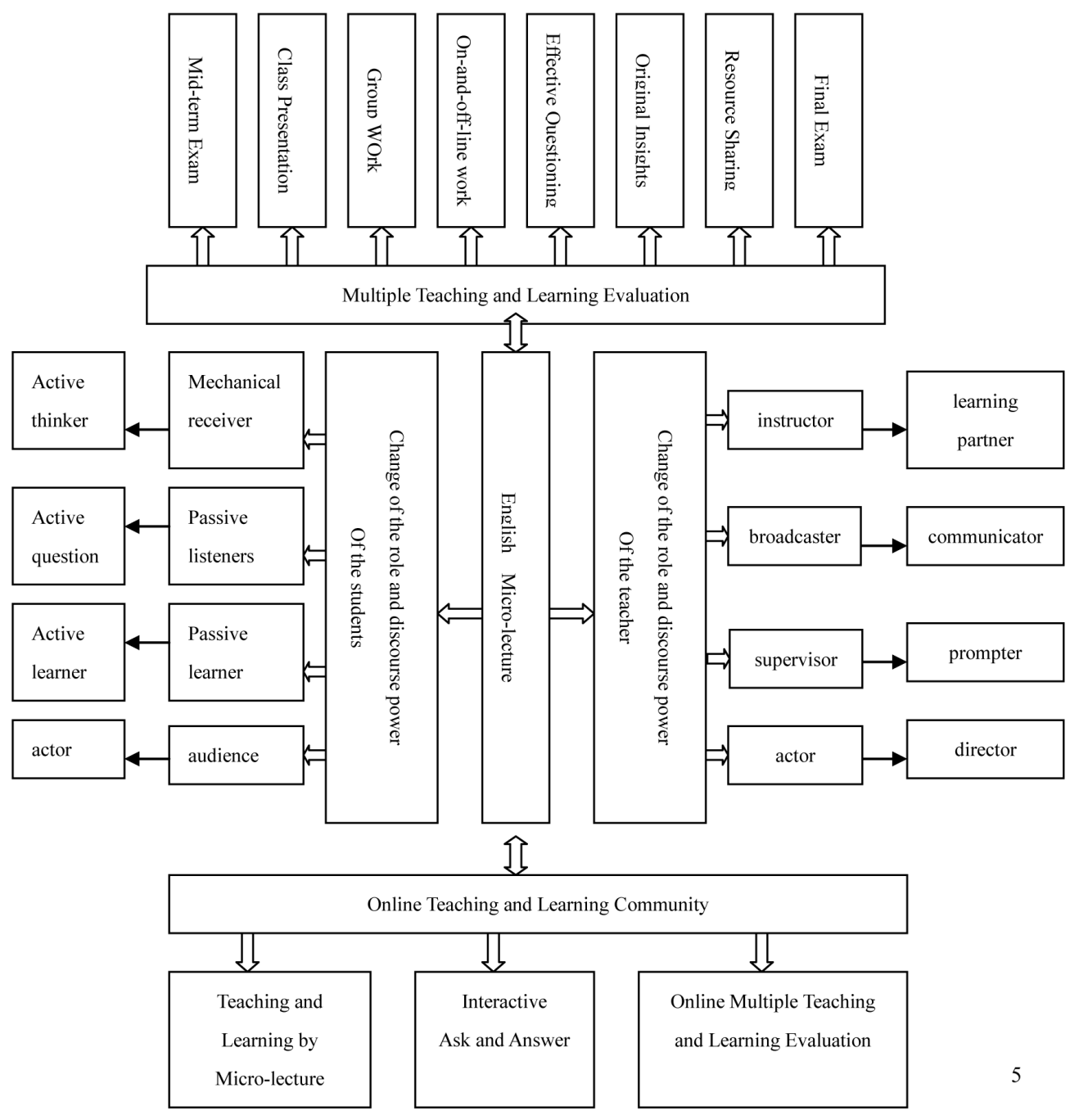

Figure 4. The harmonious ecological college English class. 
and variety. The emphasis of evaluation will change from results to process, participation and attitudes. As a result, students will acquire a good learning attitude, a good habit, a healthy and active emotion and scientific learning strategies to learn effective, efficiently and happily.

\section{Conclusion}

By using ecological teaching strategies of cooperation, competition, consideration and creativeness, students will acquire ecological learning strategies to deal with different problems in their future study (Figure 4). In other words, students will benefit from it continuously. With the help of micro-lecture, the discourse between teacher and students can be improved and the roles of teacher and students can be changed. In addition, the multiple learning and teaching evaluation and online learning and teaching community make a great contribution to that. As a result, students and teacher will enjoy themselves in class and students will study independently, participate actively, explore happily and practice courageously.

Study in class and out of class will be linked together and form a closed loop to promote college English teachers' teaching ability and influence, teachers' niche breadth.

\section{Acknowledgements}

The paper is under the project of Study on the Optimum Zone of College Students Learning in Class under the New Media Environment (GH152012). All the project members made their contributions to the paper. I also thank all my friends and classmates who live in different cities, which made the investigation possible.

\section{References}

Chapelle, C. A., \& Douglas, D. (2010). Assessing Language through Computer Technology. Cambridge: Cambridge University Pres.

Chen, J. L. (2011). The Integration of Computer and Networks into Foreign Language Curriculum - A Research Based on College English Reform. Shanghai: Shanghai Foreign Language Education Press.

Griffiths, G., \& Keohane, K. (2013). Personalizing Language Learning. Cambridge: Cambridge University Press.

Li, W. (2008). The Theory of Trend and Position of Niche and Assessment of College Teachers' Teaching Ability. Assessment of higher education in China, 3, 49.

Liu, C. J. (2014). A Study on College English Classroom Ecology in the Context of Information. Guang Zhou: World Book Publishing Guangdong Co., Ltd.

Liu, S. (2011). Classrrom Ecology - Harmony and Creation. Beijing: People’s Education Press.

White, C. (2011). Language Learning in Distance Education. Cambridge: Cambridge University Press.

Zhu, C. Q. (1997). The Theory of Trend and Position of Niche and Expansion Hypothesis. Acta Ecologica Sinica, 17, 325. 